\title{
Optimization of culture conditions by Response Surface Methodology and Unstructured kinetic modeling for L-Asparaginase production by Pseudonocardia endophytica VUK-10
}

\author{
Ushakiranmayi Managamuri $^{1}$, M. Vijayalakshmi ${ }^{*}$, V. S. Rama Krishna Ganduri ${ }^{2,3}$, R. Satish Babu ${ }^{4}$, Sudhakar Poda ${ }^{3}$ \\ ${ }^{1}$ Department of Botany and Microbiology, Acharya Nagarjuna University, Nagarjuna Nagar, Guntur-52510, Andhra Pradesh, India. \\ ${ }^{2}$ Department of Biotechnology, K L University, Green Fields, Vaddeswaram-522502, Andhra Pradesh, India. \\ ${ }^{3}$ Department of Biotechnology, Acharya Nagarjuna University, Nagarjuna Nagar, Guntur-522510, Andhra Pradesh, India. \\ ${ }^{4}$ Department of Biotechnology, National Institute of Technology, Warangal- 506004, Telangana, India.
}

\begin{tabular}{|c|c|}
\hline ARTICLE INFO & ABSTRACT \\
\hline $\begin{array}{l}\text { Article history: } \\
\text { Received on: } 13 / 08 / 2016 \\
\text { Revised on: } 22 / 09 / 2016 \\
\text { Accepted on: } 23 / 10 / 2016 \\
\text { Available online: } 31 / 01 / 2017\end{array}$ & $\begin{array}{l}\text { L-asparaginase is an anti-tumor enzyme and widely accepted as chemotherapeutic agent which has activity } \\
\text { against acute lymphoblastic leukemia. The current study targets the production of L-asparaginase by } \\
\text { Pseudonocardia endophytica VUK-10 by a statistically designed model. Experiments were performed according } \\
\text { to central composite design of RSM with five independent variables such as time, pH, temperature, } \\
\text { concentrations of maltose and L-asparagine concentration for optimization. All the five conditions had }\end{array}$ \\
\hline $\begin{array}{l}\text { Key words: } \\
\text { L-asparaginase, } \\
\text { Optimization, Response } \\
\text { Surface Methodology, } \\
\text { Unstructured kinetic model, } \\
\text { Pseudonocardia endophytica } \\
\text { VUK-10. }\end{array}$ & $\begin{array}{l}\mathrm{L}-\text { asparaginase production was recorded as } 7.42 \mathrm{IU} / \mathrm{ml} \text { slightly higher than the model predicted value of } 6.8 \\
\mathrm{IU} / \mathrm{ml} \text {, from statistical optimization studies. An unstructured kinetic model was proposed to depict the profiles } \\
\text { of biomass, substrate utilization and L-asparaginase production in optimized medium under shake flask level. } \\
\text { The logistic and Leudeking-Piret expressions were modified to predict the kinetic model parameters }\left(\mu_{\max }, X_{0} \text {, }\right. \\
\left.X_{\max }, \alpha, \beta, \gamma \text { and } \eta\right) \text { and we found that L-asparaginase production was growth-associated. High significant } \\
\text { correlation }\left(\mathrm{R}^{2}\right) \text { values of } 0.86,0.96 \text { and } 0.94 \text { were observed with the experimental and predicted results for } \\
\text { Pseudonocardia endophytica VUK-10 growth, L-asparaginase activity and Maltose utilization, respectively. } \\
\text { The results obtained from medium optimization using RSM and unstructured mathematical models describe the } \\
\text { L-asparaginase fermentation kinetics more effectively. }\end{array}$ \\
\hline
\end{tabular}

\section{INTRODUCTION}

Bacterial L-asparaginases are important enzymes which have application in treatment of acute lymphoblastic leukaemia in children (Verma et al., 2007). In addition, L-asparaginase has antioxidant property (Maysa et al., 2010) that finds application as a food processing aid in food industry. The enzyme mainly decreases the acrylamide levels up to $90 \%$ in starchy fried foods

* Corresponding Author

Vijaya Lakshmi Muvva, Department of Botany and Microbiology, Acharya Nagarjuna University, Nagarjuna Nagar, Guntur-52510, Andhra Pradesh, India. Email: profmvl08 @ gmail.com
(Hendriksen et al., 2009). L-asparaginase is an amino hydrolase enzyme that catalyses asparagine into aspartic acid and ammonia. Since the neoplastic cell cannot synthesize L-asparaginase, it has to depend on the circulatory L-asparaginase from the plasma pool (Jayaramu et al., 2010). The shortage of exogenous amino acid is coupled with impaired protein synthesis (Thomas et al., 2010). The commonest therapeutic practise is to inject the exogenous supply of the L-asparaginase intravenously to decrease concentration of asparagine in the blood (Balakrishnan et al., 2015). As the cancerous cells are devoid of the required L-asparagine, they do not survive. The currently used of commercial enzyme in the treatment of acute lymphoblastic leukaemia is L-asparaginase obtained from Escherichia coli and Erwinia carotovora. 
On the contrary, the prolonged use of this enzyme causes many side effects. Hence there is a need to screen novel microorganisms that produce high yields of this enzyme with minimal side effects. Actinobacteria are an important group that are highly explored for production of anticancer agents (Anupa et al., 2013). Several Streptomyces spp. such as Streptomyces karnatakensis, Streptomyces venezuelae, Streptomyces longsporusflavus, Streptomyces gulbargensis and marine Streptomyces sp. PDK2 have been explored for L-asparaginase (Balakrishnan et al., 2015). Cultural conditions, media composition, inoculum size, agitation rate and incubation time has profound influence on the production of L-asparaginase (Hymavathi et al., 2009). Statistical designs have been applied for the optimization experiments (El-Naggar and Abdelwahed, 2014). Since the statistical design has many advantages such as suitable for multiple factor experiments, less number of experiments, relationship between the factors and forecast response (Chang et al., 2006).

Optimization of the L-asparaginase production by the classical method is laborious in designing the experiments by one variable and keeping the value of the other variable unchanged (Adinarayana et al., 2003). The application of One-factor-at-a-time (OFAT) strategy has the limitation lag in the time required and labor intensive. Optimization is crucial step to meet the economics of the production process, not knowing the interaction of the variables influencing the enzyme production (Sowmya et al., 2015). In order to overcome the OFAT strategy exclusive statistical tools like Response Surface Methodology (RSM) can be applied.

Factorial experiments can be designed by RSM to build the mathematical models that assess the effects of several factors on the response desired. RSM is a statistical modeling and optimization approach that evaluate the interactive and synergistic effects of the given quantitative data from appropriate experiments to determine and draw solution to multivalent equations, thus providing an optimum solution to achieve the maximum output (Daramola et al., 2007; Muthuvelayudham and Viruthagiri, 2010). The advantage of RSM is the reduction of tests number required to calculate the multiple factors and their interactions, thus making it acceptable and time-efficient (Liu et al., 2013). RSM is a documented method reported for optimization of the different variables that influence the production of many enzymes such as L-asparaginase (Thenmozhi et al., 2011), Cellulase (Daunjung et al., 2015), fibrin (ogen) olytic protease (Sourav et al., 2015).

Modeling aspects using mathematical equations have become most powerful engineering tool in predicting the complex fermentation systems. The explicit information like biomass, substrate utilization and product formation obtained from these modeling studies are essential for successful design and efficient operation of fermentation process. These kinetic models allow the bioengineer to get insight and deep knowledge on the mechanism of synthesis of metabolites such as L-asparaginase for its yield and productivity from fermentation studies. Further, the evaluation of assumed unstructured models with experimental data for comparison in order to find the best model that describes the system. In general, unstructured models consider the cell mass as a whole to explain the biological system and are more effective in elucidating the fermentation profiles of microbial process for bio products (Sinclair and Kristiansen, 1987; Dhanasekar et al., 2003; Zand et al., 2004; Rajendran and Thangavel, 2008; Rama Krishna et al., 2016).

In the present study, statistical optimization technique was attempted for media development to maximize the specific activity of L-asparaginase produced by Pseudonocardia endophytica VUK-10. The optimum levels of most significant parameters were identified using central composite design experiment. Further, the kinetic model for growth and enzyme production was proposed and data fitting from shake flask fermentation was also tested.

\section{MATERIALS AND METHODS}

\section{Media used in this study}

Pseudonocardia endophytica VUK-10 strain was grown in triplicate for 7 days at $37^{\circ} \mathrm{C}$ on fermentation media (FM); FM-1, FM-2, FM-3 and FM-4 media. The components of these media included: FM-1: Sodium caseinate- $0.2 \%$, Soluble starch- $0.1 \%$, Lasparagine- $0.5 \%, \mathrm{~K}_{2} \mathrm{HPO}_{4}-0.2 \%, \mathrm{MgSO}_{4}-0.02 \%, \mathrm{FeSO}_{4}-0.01$ $\%, \mathrm{pH}-6.8$; FM-2: Yeast extract- $0.4 \%$, Glucose-1\%, Malt extract- $0.4 \%$, L-asparagine- $0.5 \%, \mathrm{pH}-7.2$; FM-3: $\mathrm{K}_{2} \mathrm{HPO}_{4}$ $0.1 \%$, Glycerol- $1 \%$, L-asparagine- $0.5 \%, \mathrm{FeSO}_{4}-0.01 \%, \mathrm{MnCl}_{2}$ $0.01 \%, \mathrm{ZnSO}_{4}-0.01 \%, \mathrm{pH}-7$ and FM-4: D- Glucose $-1 \%$, Lasparagine- $0.5 \%, \mathrm{~K}_{2} \mathrm{HPO}_{4}-0.05 \%$, Trace salts solution- $0.1 \%, \mathrm{pH}$ - 6.8, respectively. The data obtained from shake-flask fermentation runs were used in the mathematical modeling.

\section{Optimization of screened medium components by Response surface methodology}

RSM is a statistical modeling method applied for multiple regression analysis using the obtained quantitative data for designed experiment for solving the multivariable equations (Jagannadha Rao et al., 2000). It determines the optimum conditions of Pseudonocardia endophytica VUK-10 for the production of the L-asparaginase under a wide array of physical conditions. A full factorial central composite face-centered design (CCFD) for 5 independent variables was used to obtain the combination of values that optimize the response with the region of three dimensional observation spaces that allow one to design a minimal number of experiments. Design Expert software (Version 8.0.5 State-Ease, Inc., USA) was used to design the experiments for L-asparaginase production.

In order to achieve the maximum production of $\mathrm{L}$ asparaginase, the most effective variables (A, B, C, D and E) and their optimum levels were identified using Central Composite Design (CCD) of RSM. In this study, A-Time, B-pH, CTemperature, D- Maltose and E-L-asparaginase were selected as independent variables. A $2^{5}$ full factorial CCD for five variables consists of 32 factorial points, 10 axial points and 8 replicates at 
center points used for each categorical variable which includes a total of 50 experiments, were calculated from the following equation (1) (Azargohar and Dalai, 2005).

$$
N=2^{n}+2 n+n_{c}=2^{5}+2 \times 5+8=50
$$

Where $N$ is total number of experiments to be conducted, $n$ is number of factors and $n_{c}$ is number of replicates at center points.

The central coded value of all variables was considered as zero. Minimum and maximum ranges of all the variables were used for RSM and the complete experimental plan with values in actual and coded form is given in supplementary Table (1).

The data obtained was subjected to graphical and regression analysis using Design Expert Software. The experimental errors and reproducibility of the data were determined by the central points. In order to minimize the effect of the uncontrolled factors the experimental sequence was randomized. The second degree polynomial equation was used with each variable to develop an empirical model (equation 2) which correlated the response (L-asparaginase production) to five variables.

$Y=\beta_{0}+\sum_{i=1}^{n} \beta_{i} X_{i}+\left(\sum_{i=1}^{n} \beta_{i i} X_{i}\right)^{2}+\sum_{i=1}^{n-1} \sum_{j=i+1}^{n} \beta_{i j} X_{i} X_{j}$ (2)

Where $Y$ is the predicted response, $\beta_{0}$ is intercept coefficient, $\beta_{i}$ is the linear coefficient, $\beta_{i j}$ are the interaction coefficients, $\beta_{i i}$ are the quadratic coefficients, $X_{i}$ and $X_{j}$ are coded values of the five additive variables.

The model was statistically analyzed to evaluate the analysis of variance (ANOVA). In order to analyze the fit and prediction accuracy of the model constructed, Correlation Coefficients $\left(\mathrm{R}^{2}\right)$, adjusted determination coefficient (Adjusted$\mathrm{R}^{2}$ ), root mean square error (RMSE) and absolute average deviation (AAD) were carried out between experimental and predicted data.

\section{Unstructured kinetic modeling}

The rates of actinomycetes growth and carbon substrate consumption influence the L-asparaginase as primary metabolite synthesis. Basic mathematical and unstructured kinetic models quantitatively describe the substrate utilization kinetics and growth-associated product formation kinetics in a batch system and the equations were developed by researchers (Mohammad et al., 1995; Klimek and Ollis, 1980; Thomson and Ollis, 1980; Cheng et al., 2010).

Under optimal growth conditions and no effects of substrate and product inhibition, growth kinetic model of Pseudonocardia endophytica VUK-10 (X) (as per Malthus's law), in a batch fermentation is best described as:

$$
\frac{d X}{d t}=\mu_{\max } X\left(1-\frac{X}{X_{m}}\right)
$$

On integration above equation gives the Logistic (L)- type model equation that relates hyperbolic growth of cell:
$X(t)=\frac{X_{0} e^{\mu_{\max } t}}{1-\frac{X_{0}}{X_{m}}\left(1-e^{\mu_{\max t}}\right)}$

Maximum specific growth rate, $\mu_{\max }$, can be obtained from slope of plot of $\ln \left(\frac{X_{t}\left(X_{m}-X_{0}\right)}{X_{0}\left(X_{m}-X(t)\right.}\right)$ vs $t$.

L-asparaginase production can be obtained from growth limiting substrate and the substrate utilization kinetics can be taken from Modified Leudeking-Piret (MLP) equation:

$-\frac{d S}{d t}=r_{S}=\gamma\left(\frac{d X}{d t}\right)+\eta X$

On integration above equation results Logistic Incorporated Modified Leudeking-Piret (LIMLP) equation:

$S(t)=S_{0}-\gamma\left[\frac{X_{0} e^{\mu_{\max } t}}{1-\left(\frac{X_{0}}{X_{m}}\right)\left(1-e^{\mu_{\max } t}\right)}-X_{0}\right]+\frac{\eta X_{m}}{\mu_{\max }} \ln [1-$

XOXm1-eumaxt (6)

Constant of non-growth associated substrate consumption, $\eta$, in above equation can be calculated from stationary phase data

$$
\text { (where } \frac{-d S}{d t}=0 \text { ): } \eta=\frac{-\left(\frac{d S}{d t}\right)_{\text {stationary phase }}}{x_{\max }}
$$

Growth associated substrate consumption constant, $\gamma$ can be obtained from slope of plot of

$\left(S_{0}-S(t)\right)+$

$\frac{\eta X_{m}}{\mu_{\max }} \ln \left[1-\left(\frac{X_{0}}{X_{m}}\right)\left(1-e^{\mu_{\max } t}\right)\right] \mathrm{vs}\left[\frac{X_{0} e^{\mu_{\max t}}}{1-\left(\frac{X_{0}}{X_{m}}\right)\left(1-e^{\mu_{\max } t}\right)}-X_{0}\right]$.

Significant product formation occurs in late-logarithmic phase of cell growth and L-Asparaginase, product formation kinetics follows Leudeking-Piret equation, as:

$\frac{d P}{d t}=\alpha \frac{d X}{d t}+\beta X$

Logistic Incorporated Leudeking-Piret (LILP) equation derived from integration of above equation results:

$$
\begin{aligned}
& P(t)=P_{0}+\alpha\left[\frac{X_{0} e^{\mu_{\max t}}}{1-\left(\frac{X_{0}}{X_{m}}\right)\left(1-e^{\mu_{\max } t}\right)}-X_{0}\right]+\frac{\beta X_{m}}{\mu} \ln [1- \\
& \text { XOXm1-eumaxt (9) }
\end{aligned}
$$

Non-growth associated product formation constant, $\beta$, can be determined from stationary phase data

$$
\begin{gathered}
\text { (where } \left.\frac{d X}{d t}=0\right): \beta=\frac{\left(\frac{d P}{d t}\right)_{\text {stationary phase }}}{X_{\max }} \\
\text { A plot of }\left(P(t)-P_{0}\right)+\frac{\beta X_{m}}{\mu} \ln \left[1-\left(\frac{X_{0}}{X_{m}}\right)\left(1-e^{\mu_{\max } t}\right)\right] \mathrm{vs} \\
{\left[\frac{X_{0} e^{\mu_{\max } t}}{1-\left(\frac{X_{0}}{X_{m}}\right)\left(1-e^{\mu_{\max } t}\right)}-X_{0}\right]}
\end{gathered}
$$

Yields growth-associated parameter, $\alpha$ as slope. 
Experimental data obtained from batch shake-flask fermentations using different carbon substrate media (FM-1, 2, 3 and 4) was used to simulate using the equations (4), (6) and (9).

\section{RESULTS AND DISCUSSION}

\section{L-asparaginase production}

Experimental production of L-asparaginase by five variables and one response by a complete five factors and five levels of factorial design with three replications of the central point and three axial points were shown in supplementary Table (1). From the experimental cultural conditions, maximum production of L-asparaginase by Pseudonocardia endophytica VUK-10 was found to be $7.42 \mathrm{IU} / \mathrm{ml}$ from run of 50 are as follows: Time @ 96 h, pH @ 8, Temperature @ $30{ }^{\circ} \mathrm{C}$, Maltose concentration @ 1\% w/v and L-asparagine concentration @ 1\% w/v.

\section{RSM Modeling}

In order to check the accuracy of the model whether the model would give poor or misleading results, Model Adequacy checking was executed. To analyze the actual relationship between response (yield of L-asparaginase) and the variables for highdegree polynomial models, viz. linear, interactive (two factorial), quadratic and cubic models were fitted into the experimental data. Sequential model sum of squares, lack of fit tests and model summary statistics were applied to study the adequacy of models among various models and the results obtained are represented in supplementary Table (2).

The quadratic model as per sequential model sum of squares was found to be significant (p-value $<0.0001$ ). Lack of fit tests values from sequential model fitting for the quadratic model did not show significant lack of fit. Adjusted $\mathrm{R}^{2}$ and Predicted $\mathrm{R}^{2}$ for this quadratic model came out as the best model. Hence, the full quadratic polynomial model (Eq. 11) in terms of actual factors obtained was:

$Y=-80.36058+0.15947 * A+19.20758 * B+0.22002 * C-$
$2.66984 * D+2.25168 * E$
$005 * A C+3.4375 \mathrm{E}-004 * A D-6.875 \mathrm{E}-04 * A E+1.65 \mathrm{E}-003 * B C-$
$0.016^{*} B D+0.033 * B E-8.25000 \mathrm{E}-004 * C D+1.65000 \mathrm{E}-003 * C E-$
$0.0165 * D E-8.13458 \mathrm{E}-004 * A 2-1.20221^{*} B 2-3.68552 \mathrm{E}-$
$003 * C 2+0.6424{ }^{*} D 2-1.35821 * E 2$

F-value of 12.79 from the computed model indicates that the model is significant and there is only $0.01 \%$ chance that a model F-value this large could occur due to noise.

The model p-Value $(<0.0001)$ for the ANOVA analysis, coeffcient of determation $\left(\mathrm{R}^{2}=0.89\right)$ and adjusted coefficient of determation (adjusted $\mathrm{R}^{2}=0.82$ ), the quadratic polynomial model is highly significant and can be used to exhibit the relation between response and the significant variables as shown in the supplementary Table (3). This model is useful to asses the direct interaction and the quadratic effects in optimizing the parameters for increasing the L-asparaginase production.

\section{Effect of variables on the production of L-asparaginase by Pseudonocardia endophytica VUK-10}

Based on the data from supplementary Table (3), effect of the five variables with linear square and quadratic coefficient were recorded as significant. Time, $\mathrm{pH}$, Temperature, Maltose and L-asparagine as individual factors had high coefficient value which indicate that high linear significant effect on the Lasparaginase production. Direct influence of the five variables (Time, pH, Temperature, Maltose and L-asparagine) on the response (L-asparaginase) production were documented. The production of L-asparaginase started from $24 \mathrm{~h}$ and reached maximum at $96 \mathrm{~h}$, further the production of L-asparaginase decreased as the time increased. Results from the study of Narayana et al. (2008) showed that maximum enzyme production by $S$. albidoflavus obtained after $96 \mathrm{~h}$. Influence of $\mathrm{pH}$ on the production of L-asparaginase was recorded with Pseudonocardia endophytica VUK-10 grown at different $\mathrm{pH}$ ranges between 6 and 9. The maximum production was recorded at $\mathrm{pH}$ 8. Enzyme production decreased with further increase in $\mathrm{pH}$. Dhevagi and Poorani (2006) reported that maximum L-asparaginase production by Streptomyces sp. PDK7 was observed between $\mathrm{pH} 8$ and 8.5.

A steady increase in L-asparaginase production was observed with increase in temperature from $20{ }^{\circ} \mathrm{C}$ and reached maximum at $30{ }^{\circ} \mathrm{C}$. Further increase in temperature resulted in decline in production of the enzyme. Selvam and Vishnupriya (2013) and Jayaramu et al. (2010) reported that the production was optimum between $28{ }^{\circ} \mathrm{C}$ and $30^{\circ} \mathrm{C}$.

Among the carbon sources tested, maltose @ 1\% was found to significantly enhance L-asparaginase production when the strain was grown at $\mathrm{pH} 8$, for $96 \mathrm{~h}$ at $30{ }^{\circ} \mathrm{C}$. These results are in agreement with the results reported by Amena et al. (2010), suggesting maximum L-asparaginase production by $S$. gulbargensis with maltose. Sivasankar et al. (2013) stated that maltose was the ideal source of carbon for L-asparaginase production.

Maximum production of the enzyme was obtained when the fermentation medium was supplemented with $1 \%$ maltose by Streptomyces albidoflavus (Narayana et al., 2008). L-asparagine @ 1\% was found to produce highest level of the enzyme. Amena et al. (2010) and Warangkar and Khobragade (2009) reported that the maximum production of the enzyme was observed with Lasparagine between $0.5 \%$ and $1 \%$.

The optimum conditions that influence the production of L-asparaginase by Pseudonocardia endophytica VUK-10 include Time $96 \mathrm{~h}, \mathrm{pH}$ 8, temperature $30{ }^{\circ} \mathrm{C}$, Maltose $1 \%$ and L-asparagine $1 \%$.

\section{Interactive and Quadratic effects on L-asparaginase production}

Optimum levels for each variable were determined for maximum production of L-asparaginase. Three-dimension response surface plots were constructed with response (Lasparaginase production) on $\mathrm{z}$ axis against two independent 
variables with other variables at constant. The optimum production of L-asparaginase was recorded at the middle of each pair of variables with the other variable constant at the middle. Further increase in this variable above the middle level recorded in decreased production of L-asparaginase.

According to supplementary Table (3), the effect of each parameter such as Time, $\mathrm{pH}$ and Temperature, concentrations of maltose and L-asparagine on the production of L-asparaginase was insignificant; all the five parameters had important and significant interactions with other parameters. The significant interactive effects of the variables (AB- Time and $\mathrm{pH}, \mathrm{AC}$ - Time and Temperature, AD- Time and maltose, AE- Time and L-asparagine, BC- $\mathrm{pH}$ and Temperature, BD- $\mathrm{pH}$ and Maltose, BE- $\mathrm{pH}$ and Lasparagine, CD- Temperature and Maltose, CE- Temperature and L-asparagine and DE- Maltose and L-asparagine) are presented as $3 \mathrm{D}$ surface plots as shown in Figure 1. In addition, the quadratic effects of the five variables on the L-asparaginase production (Response) were significant. Maximum production of Lasparaginase was recorded to be $7.42 \mathrm{IU} / \mathrm{ml}$ slightly higher than the model predicted value $6.8 \mathrm{IU} / \mathrm{ml}$.

The profiles of Pseudonocardia endophytica VUK-10 growth, substrate concentrations in different media (FM-1, FM-2, FM-3 and FM-4) and L-asparaginase activity obtained from shake flask fermentations and model kinetics were compared in Fig. (2, 3, 4 and 5). From all the profiles, it was observed that model predicted and experimental values show good fit. In this study, for fitting of experimental data with unstructured Logistic models, nonlinear regression using least-square method was done with the help of Microsoft Excel Solver 2010. Biokinetic parameters used in the mathematical model equations (4), (6) and (9) were also estimated and are tabulated in supplementary Table (4).

It also shows determination coefficient $\left(\mathrm{R}^{2}\right)$ values obtained by fitting Logistic (L), Logistic Incorporated Leudeking-Piret (LILP) and Logistic Incorporated Modified Leudeking-Piret (LIMLP) models to the experimental data were found to be high, thus revealing good precision of the models.
For all the different media (FM-1, FM-2, FM-3 and FM4) used in this study, $\mu_{\max }, X_{0}$ and $X_{\max }$ were calculated for Pseudonocardia endophytica VUK-10 growth kinetic profile using Logistic (L) model. Values of growth and non-growth associated product parameters, $\alpha$ and $\beta$, were estimated using LILP model and a higher $\alpha$ value than $\beta$ confirmed that L-asparaginase production by Pseudonocardia endophytica VUK-10 is more growth associated than non-growth associated in shake flask. The simulated parameters, $\gamma$ and $\eta$, of LIMLP model are also in good agreement with the experimental values, implies that this model is more appropriate to represent different carbon (Starch in FM-1, Glycerol in FM-2, Glucose in FM-3 and FM-4) utilization kinetics in L-asparaginase production by $P$. endophytica VUK-10.

From the carbon source optimization studies, it was found that $1 \%(\mathrm{w} / \mathrm{v})$ Maltose containing medium had shown highest L-asparaginase activity $(7.42 \mathrm{IU} / \mathrm{ml})$. To understand the kinetic behavior of $P$. endophytica VUK-10 with $1 \%$ Maltose in medium, the same unstructured model was used for estimating simulated kinetic parameters. Figure (6) shows the good fit of experimental and simulated results obtained using L, LILP and LIMLP models for kinetic profile of $P$. endophytica VUK-10 growth, Maltose utilization and L-asparaginase activity. (Supplementary Table 4) also shows kinetic parameters $\mu_{\max }, X_{0}$, $X_{\max }, \alpha, \beta, \gamma$ and $\eta$ values. L-asparaginase activity from experiment value $(7.42 \mathrm{IU} / \mathrm{ml})$ is slightly higher than model predicted value (6.96 IU/ml). Thus, the unstructured models provided a better approximation of kinetic profiles of L-asparaginase production by Pseudonocardia endophytica VUK-10 in submerged shake flask fermentations. To the best of our knowledge, this is the first report on the kinetic modeling for L-asparaginase production under optimized carbon substrates using different medium constituents by Pseudonocardia endophytica VUK-10. Few other reports are also available on L-asparaginase (Sanjeeviroyar et al., 2010; Mungi et al., 2014; Arrivukkarasan et al., 2010) using different microbes.
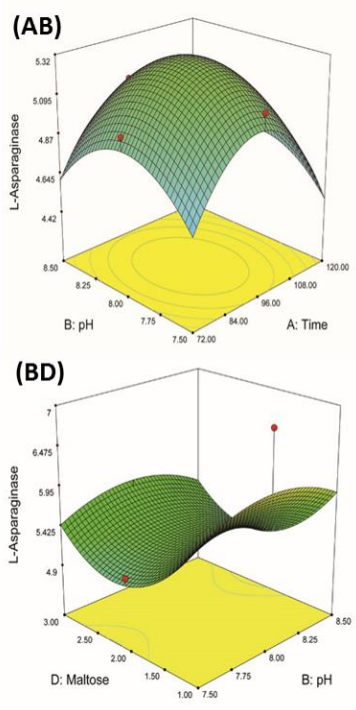
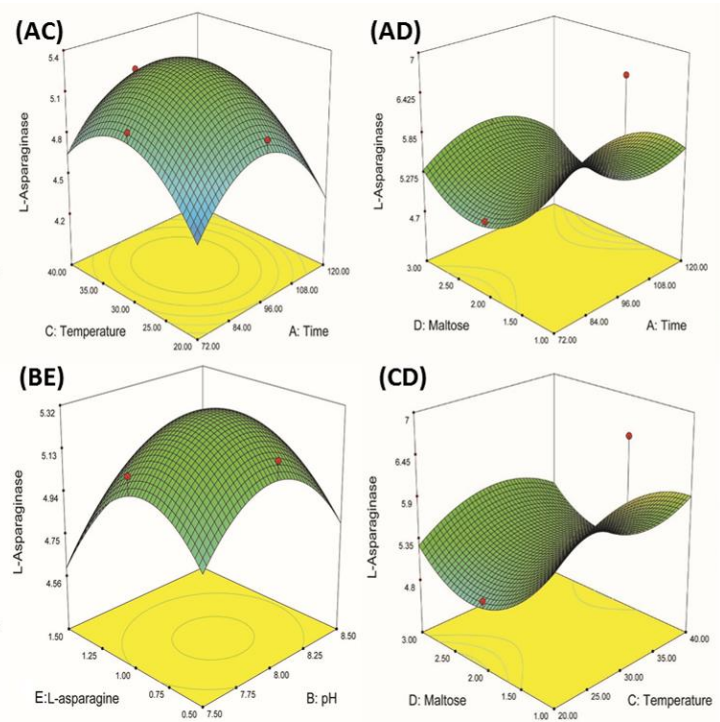
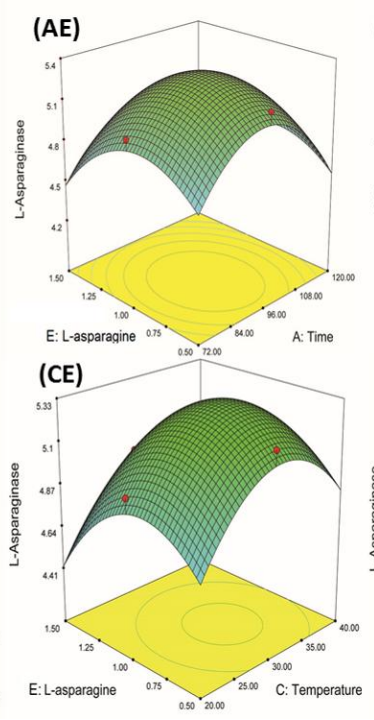
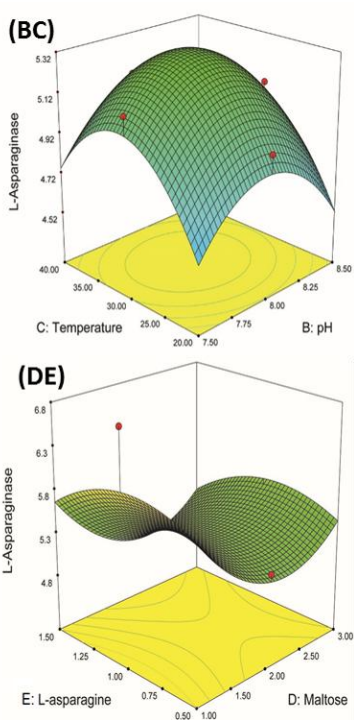

Fig. 1: Response surface plots (3-dimensional view) showing interactive effects of selective variables on $\mathrm{L}$-asparaginase production (AB) Time and pH, (AC) Time and Temperature e, (AD) Time and Maltose (AE) Time and L-Asparagine (BC) pH and Temperature (BD) pH and Maltose (BE) pH and L-asparagine

(CD) Temperature and Maltose (CE) Temperature and L-Asparagine (DE) Maltose and L-Asparagine. 


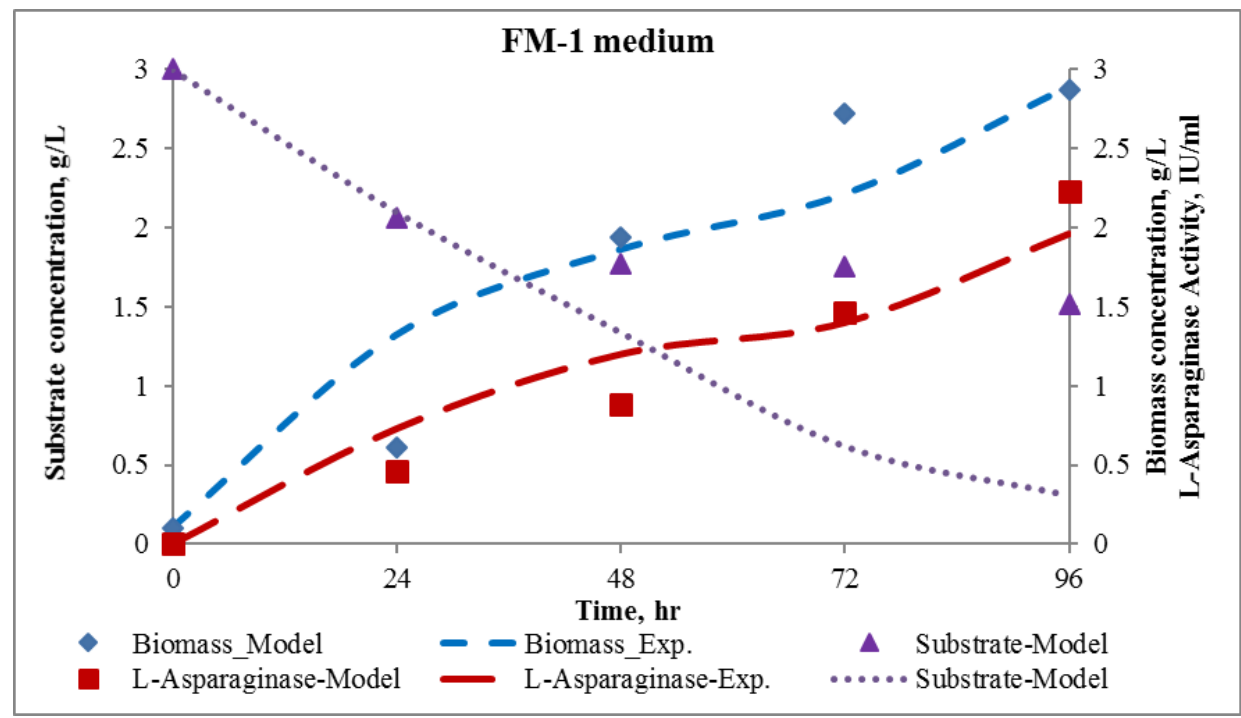

Fig. 2: Experimental and model predicted kinetics of biomass, substrate utilization and L- asparaginase activity using FM-1 medium.

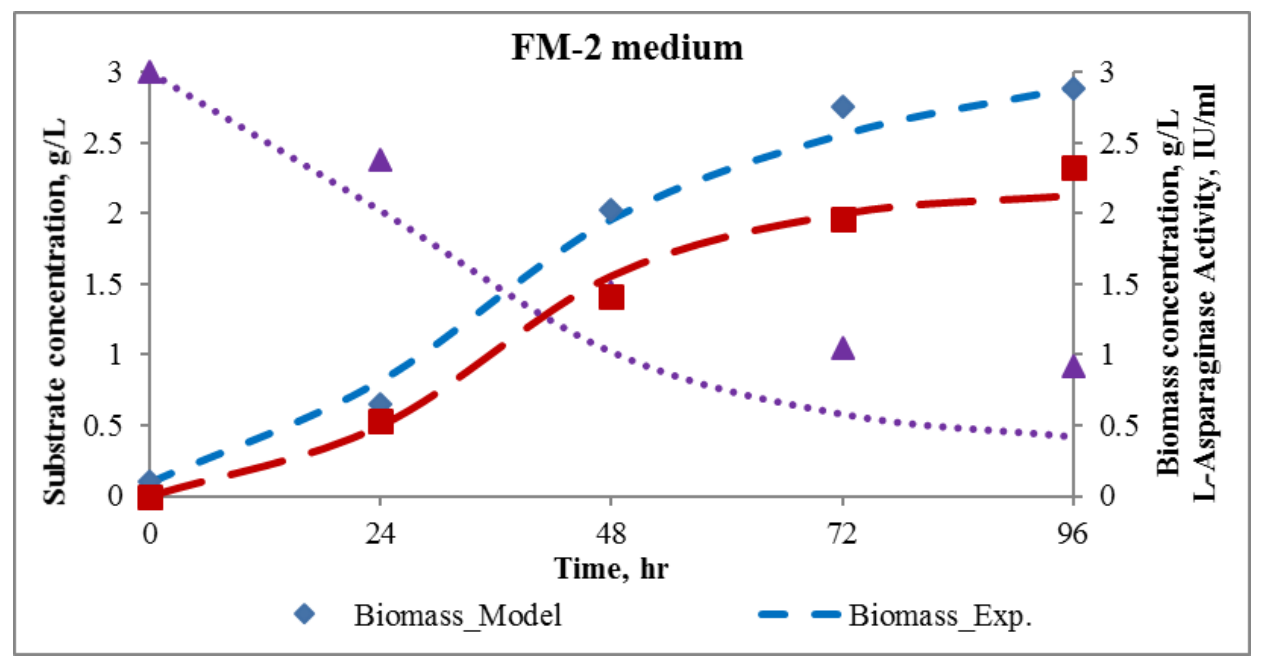

Fig. 3: Experimental and model predicted kinetics of biomass, substrate utilization and L-asparaginase activity using FM-2 medium.

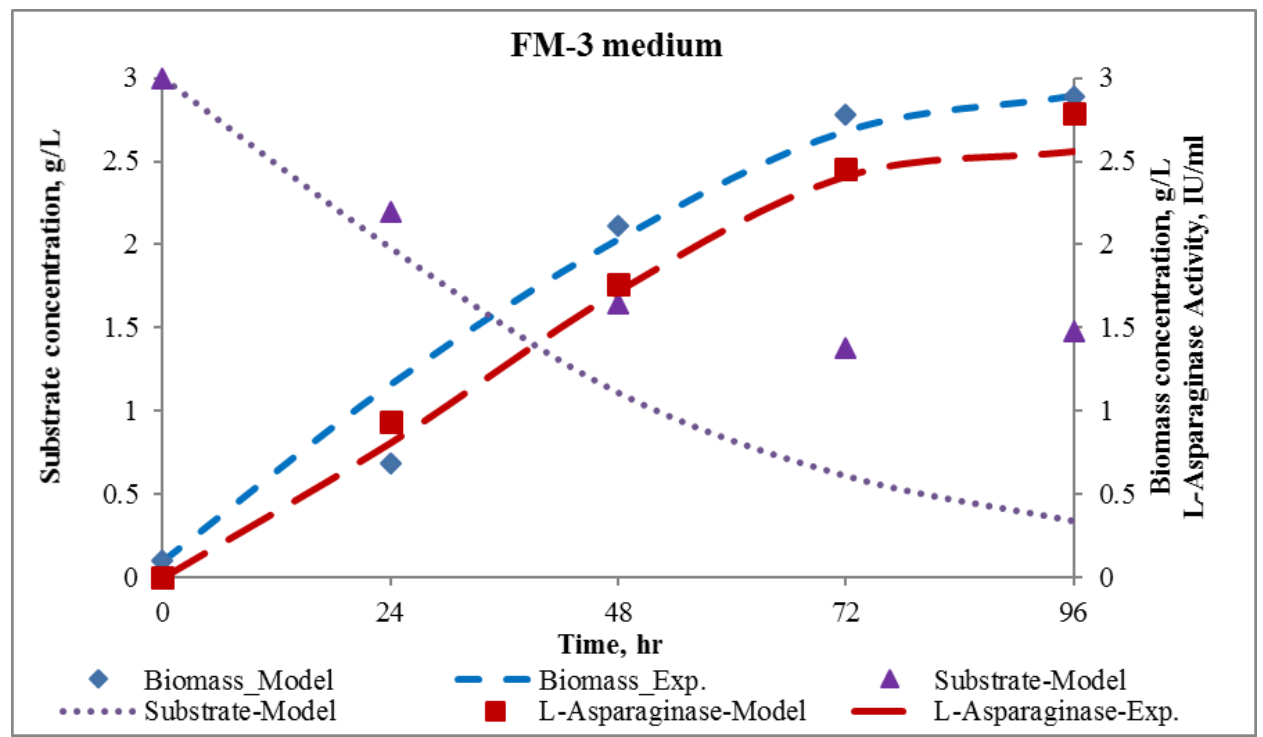

Fig. 4: Experimental and model predicted kinetics of biomass, substrate utilization and L-asparaginase activity using FM-3 medium. 


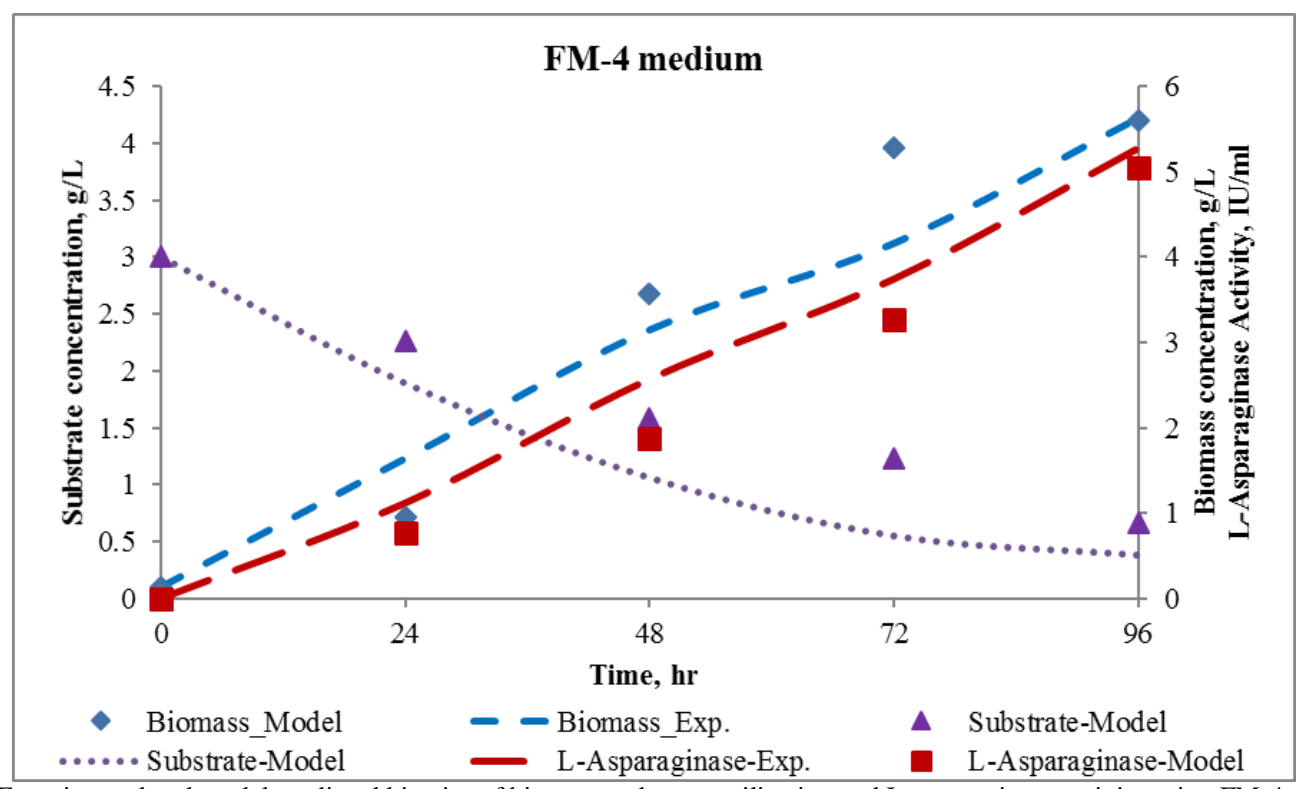

Fig. 5: Experimental and model predicted kinetics of biomass, substrate utilization and L-asparaginase activity using FM-4 medium.

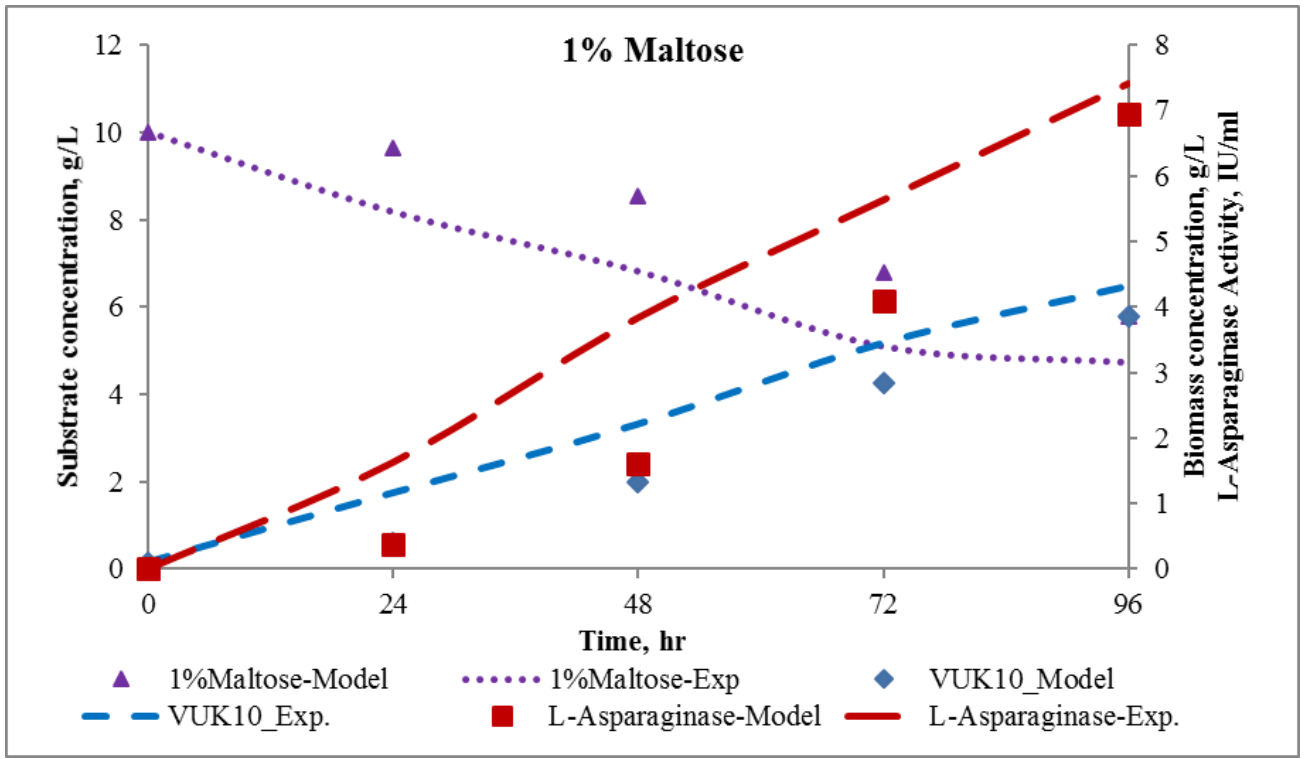

Fig. 6: Experimental and model predicted kinetics of biomass, substrate utilization and L-asparaginase activity using optimized Maltose (1\% w/v) medium.

\section{CONCLUSION}

The present study was aimed at applying the statistical experimental design to optimize the physical variables for the enhanced production of L-asparaginase from Pseudonocardia endophytica VUK-10. Five variables including time, $\mathrm{pH}$, temperature, Maltose and L-asparagine were optimized using central composite design of RSM. Of the five variables tested for correlation among them and the production of L-asparaginase, all the five variables demonstrated significant influence on the enzyme production as represented from the surface plots. Maximum production of L-asparaginase was recorded as 7.42 $\mathrm{IU} / \mathrm{ml}$ slightly higher than the model predicted value of $6.8 \mathrm{IU} / \mathrm{ml}$ and optimum conditions for the production of L-asparaginase by
Pseudonocardia endophytica VUK-10 are Time @ 96 h, pH @ 8, temperature@30 $@ 3$, concentration of maltose @ $1 \%$ and concentration of L-asparagine @ 1\%. For optimization, the selected factors were statistically designed to test the effects of the variables interactions with minimum number of experiments for maximizing the L-asparaginase production. A very high close similarity was observed between the predicted and experimental values which directly reflected the accuracy and applicability of the RSM in optimizing the process parameters in L-asparaginase production. From the unstructured mathematical modelling of $\mathrm{L}$ asparaginase, the data obtained from model was found as the best fit with experimental data. The estimated kinetic parameters were also significant and the maximum L-asparaginase activity using optimized conditions with $1 \%$ maltose was determined from 
model prediction as $6.96 \mathrm{IU} / \mathrm{ml}$ (7.42 IU/ml from experiment). Hence, both kinetic modelling and RSM approaches represent in good way for design and optimization of therapeutically important enzyme (L-asparaginase) from Pseudonocardia endophytica VUK-10.

\section{ACKNOWLEDGMENTS}

Financial support and sponsorship: This work is supported by the financial assistance from the University Grants Commission of India (UGC), New Delhi.

Conflict of Interests: There are no conflicts of interest.

\section{REFERENCES}

Adinarayana K, Ellaiah P, Srinivasulu B, Devi RB, Adinarayana G. Response surface methodological approach to optimize the nutritional parameters for neomycin production by Streptomyces marinensis under solid-state fermentation. Process Biochem, 2003; 38 (11): 1565-1572.

Amena S, Vishalakshi N, Prabhakar M, Dayanand A, Lingappa K. Production, purification and characterization of L-asparaginase from Streptomycetes gulbargensis. Braz J Microbiol, 2010; 41(1): 173-178.

Anupa MP, Sangeetha VS, Praseetha PK, Emelda JJ, Jabaslin EE, Sugunan VS. Anticancer agents from actinomycetes enhance therapy of tumor induced mice. J Microbiol Biotechnol Res, 2013; 3 (2): 41-50.

Arrivukkarasan S, Muthusivaramapandian M, Aravindan R, Viruthagiri T. Effect of medium composition and kinetic studies on extracellular and intracellular production of $\mathrm{L}$-asparaginase from Pectobacterium carotovorum. Food Sci Technol Int, 2010; 16 (2): 115125.

Azargohar R, Dalai AK. Production of activated carbon from Luscar char: experimental and modeling studies. Microporous and mesoporous materials. 2005 Nov 7;85(3):219-25.

Meena B, Anburajan L, Sathish T, Raghavan RV, Dharani G, Vinithkumar NV, Kirubagaran R. 1-Asparaginase from Streptomyces griseus NIOT-VKMA29: optimization of process variables using factorial designs and molecular characterization of 1-asparaginase gene. Scientific reports. $2015 \mathrm{Jul} 24 ; 5$.

Chang CY, Lee CL, Pan TM. Statistical optimization of medium components for the production of Antrodia cinnamomea AC0623 in submerged cultures. Applied microbiology and biotechnology. 2006 Oct 1;72(4):654-61.

Cheng KC, Demirci A, Catchmark JM, Puri VM. Modeling of pullulan fermentation by using a color variant strain of Aureobasidium pullulans. Journal of food engineering. 2010 Jun 30; 98(3):353-9.

Jung DU, Yoo HY, Kim SB, Lee JH, Park C, Kim SW. Optimization of medium composition for enhanced cellulase production by mutant Penicillium brasilianum KUEB15 using statistical method. Journal of Industrial and Engineering Chemistry. 2015 May 25; 25:14550 .

Dhanasekar R, Viruthagiri T, Sabarathinam PL. Poly (3hydroxy butyrate) synthesis from a mutant strain Azotobacter vinelandii utilizing glucose in a batch reactor. Biochemical engineering journal. 2003 Oct 31;16(1):1-8.

Dhevagi P, Poorani E. Isolation and characterization of Lasparaginase from marine actinomycetes. Indian journal of Biotechnology. 2006 Oct;5(4):514.

El-Naggar NE, Abdelwahed NA. Application of statistical experimental design for optimization of silver nanoparticles biosynthesis by a nanofactory Streptomyces viridochromogenes. Journal of Microbiology. 2014 Jan 1;52(1):53-63.

Hymavathi M, Sathish T, Rao CS, Prakasham RS. Enhancement of L-asparaginase production by isolated Bacillus circulans (MTCC 8574) using response surface methodology. Applied biochemistry and biotechnology. 2009 Oct 1;159(1):191-8.
Jagannadha Rao K, Chul-Ho Kim, Sang-Ki Rhee. Statistical optimization of medium for the production of recombinant hirudin from Saccharomyces cerevisiae using response surface methodology. Process Biochem., 2000; 35(7): 639-647.

Jayaramu M, Hemalatha NB, Rajeshwari CP, Siddalingeshwara KG, Mohsin SM, Sunil Dutt PLNSN. A novel approach for detection, confirmation and optimization of L-asparaginase from Emericella nidulans. Curr Pharm Res, 2010; 1(1): 20-24.

Klimek J, Ollis DF. Extracellular microbial polysaccharides: Kinetics of Pseudomonas sp. Azotobacter vinelandii and Aureobasidium pullulans batch fermentations. Biotechnol Bioeng, 1980; 22(11): 23212342.

Liu X, Mu T, Sun H, Zhang M, Chen J. Optimization of aqueous two-phase extraction of anthocyanins from purple sweet potatoes by response surface methodology. Food Chem, 2013; 141(3): 3034-3041.

Maysa EM, Amira M, Gamal E, Sanaa T, Sayed EI. Production, immobilization and anti-tumor activity of L- asparaginase of Bacillus spp. R36. J Amer Sci, 2010; 6(8): 157-165.

Mohammad FHA, Badr-Eldin SM, El-Tayeb OM, Abd ElRahman OA. Polysaccharide production by Aureobasidium pullulans III. The influence of initial sucrose concentration on batch kinetics. Biomass Bioene. 1995; 8(2): 121-129.

Mungi H, Carvalho R, Ilegar S, Ratnamala GM, Priya VS. Optimization of L-asparaginase production from Pseudomonas fluorescens by Response Surface Methodology. Int J Curr Microbiol Appl Sci, 2014; 3(11): 350-362.

Muthuvelayudham T, Viruthagiri R. Application of central composite design based response surface methodology in parameter optimization and on cellulase production using agricultural waste. Int $\mathbf{J}$ Chem Biol Eng, 2010; 3(4): 97-104.

Narayana KJP, Kumar KG, Vijayalakshmi M. L-asparaginase production by Streptomyces albidoflavus. Ind J Microbiol. 2008; 48(3): $331-336$

Poonkuzhali K, Palvannan T. Thermo stabilization of laccase by polysaccharide additives: Enhancement using central composite design of RSM. Carb Pol, 2011; 86(2): 860-864.

Rajendran A, Thangavelu V. Evaluation of various unstructured kinetic models for the production of protease by Bacillus sphaericus MTCC 511. Eng Life Sci. 2008; 8(2): 179-185.

Rafigh SM, Yazdi AV, Vossoughi M, Safekordi AA, Ardjmand M. Optimization of culture medium and modeling of curdlan production from Paenibacillus polymyxa by RSM and ANN. Int J Biol Macromol. 2014; 70: 463-473.

Rama Krishna VSG, Ushakiranmayi M, Vijayalakshmi M, Sudhakar P. Model-based kinetic parameters estimation in batch Pullulan fermentation using Jaggery as substrate. J Chem Pharma Res. 2016; 8(3): $217-224$

Sanjeeviroyar A, Rajendran A, Muthuraj M, Basha KM, Thangavelu V. Sequential optimization and kinetic modeling of L-asparaginase production by Pectobacterium carotovorum in submerged fermentation. Asia-Pac J Chem Eng. 2010; 5(5): 743-755.

Selvam K, Vishnupriya B. Partial purification and cytotoxic activity of L-asparaginase from Streptomycetes acrimycini NGP. Int J Res Pharm Biomed Sci. 2013; 4(3): 859-869.

Shahbaz Mohammadi H, Mostafavi SS, Soleimani S, Bozorgian S, Pooraskari M, Kianmehr A. Response surface methodology to optimize partition and purification of two recombinant oxidoreductase enzymes, glucose dehydrogenase and d-galactose dehydrogenase in aqueous two-phase systems. Protein Express Purif. 2015; 108: 41-47.

Sinclair CG, Kristiansen B. 1987. Fermentation kinetic and modeling. Open Univ. Press, Milton Keynes, UK.

Sivasankar P, Sugesh S, Vijayanand P, Sivakumar, K, Vijayalakshmi T, Balasubramanian T, Mayavu P. Efficient production of L-asparaginase by marine Streptomycetes sp. isolated from Bay of Bengal, India. Afr J Microbiol Res. 2013; 7(31): 4015-4021.

Sourav M, Samanwita G, Chenole K, Sudhir KR, Ashis KM. Statistical optimization for improved production of fibrin(Ogen)olytic 
enzyme by Bacillus cereus strain FF01 and assessment of in vitro thrombolytic potential of protease enzyme. Biocatal Agri Biotechnol. 2015; 4(2): 191-198.

Sowmya BJ, Prashant KB, Padma BD. Statistical media optimization for enhanced production of fibrinolytic enzyme from newly isolated Proteus penneri SP-20. Biocatal Agri Biotechnol. 2015; 4(3): 370-379.

Thenmozhi C, Sankar R, Karuppiah V, Sampathkumar P. Lasparaginase production by mangrove derived Bacillus cereus MAB5: optimization by response surface methodology. Asian Pac J Trop Med. 2011; 4(6): 486-491.

Thomas X, Cannas G, Chelghoum Y, Gougounon A. Therapeutic alternatives to native L-asparaginase in the treatment of adult acute lymphoblastic leukemia. Bull Cancer. 2010; 97(9): 1105-1117.

Thomson N, Ollis DF. Extracellular microbial polysaccharides. II. Evolution of broth Power-law parameters for xanthan and pullulan batch fermentation. Biotechnol Bioeng. 1980; 22(4): 875-883.

Verma N, Kumar K, Kaur G, Anand S. L-asparaginase: a promising chemotherapeutic agent. Crit RevBiotechnol. 2007; 27(1): 4562.
Warangkar SC, Khobragade CN. Screening, enrichment and media optimization for L-apsaraginase production. J Cell Tissue Res. 2009; 9(3): 1963-1968.

Znad H, Blazej M, Bales V, Markos J. A kinetic model for gluconic acid production by Aspergillus niger. Chem Pap. 2004; 58(1): 23-28.

\section{How to cite this article:}

Managamuri U, Vijayalakshmi M, Gandur VSRK, Satish Babu R, Poda S. Optimization of culture conditions by Response Surface Methodology and Unstructured kinetic modeling for LAsparaginase production by Pseudonocardia endophytica VUK-10. J App Pharm Sci, 2017; 7 (01): 042-050. 